\title{
Study of the influence of cellulose derivatives on physical and analytical attributes of a drug product belonging to BCS class II
}

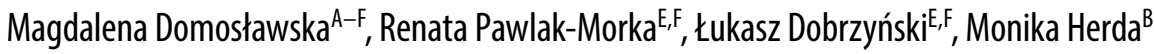 \\ Gedeon Richter Sp. z 0.0., Research and Development Department, Grodzisk Mazowiecki, Poland \\ A - research concept and design; $\mathrm{B}$ - collection and/or assembly of data; $\mathrm{C}$ - data analysis and interpretation; \\ $D$ - writing the article; $E$ - critical revision of the article; $F$ - final approval of the article
}

Address for correspondence

Magdalena Domosławska

E-mail: magda.domoslawska@gmail.com

Funding sources

None declared

Conflict of interest

None declared

Received on November 22, 2018

Reviewed on February 7,2019

Accepted on February 17, 2019
Cite as

Domosławska M, Pawlak-Morka R, Dobrzyński Ł, Herda M. Study of the influence of cellulose derivatives on physical and analytical attributes of a drug product belonging to BCS class II. Polim Med. 2018;48(2):83-90. doi:10.17219/pim/104462

DOI

10.17219/pim/104462

Copyright

○ 2019 by Wroclaw Medical University

This is an article distributed under the terms of the

Creative Commons Attribution 3.0 Unported (CC BY 3.0)

(https://creativecommons.org/licenses/by/3.0/)

\section{Abstract}

Background. Cellulose microcrystalline (MCC), hydroxypropyl methylcellulose (HPMC) and croscarmellose sodium are cellulose derivatives which are widely used in pharmaceutical technology. Although they are inert pharmaceutical ingredients, they can influence the release profile of an active substance from the dosage form depending on their distribution, type and quantity used in the formulation.

Objectives. The aim of the present investigation was to examine the effect of chosen cellulose derivatives on the physical and analytical attributes of a drug product containing an active substance of Biopharmaceutics Classification System (BCS) class II.

Material and methods. The tablets were prepared using the wet granulation technology. The batches differed in the amount and grade of HPMC, the type of MCC and the distribution of croscarmellose sodium. The granule properties as well as physical (tablet hardness, disintegration time, friability) and analytical (dissolution profile in different media) attributes of the tablets were examined.

Results. The flow characteristics were satisfying in the case of all prepared batches. However, the differences in flow properties were visible, especially in the cases where MCC of coarser particles was replaced with MCC of finer particles. The type of MCC used in the product formula also had a significant influence on the drug product dissolution profile. The batches in which MCC of finer particles was used had substantially better results, regardless of HPMC viscosity type and the distribution of croscarmellose sodium between the inner and outer phase. What is more, the differences in the results between batches of different MCC types were especially visible in dissolution conditions, i.e., $0.1 \mathrm{~N}$ hydrochloric acid (HCl).

Conclusions. By choosing the right type, quantity and distribution of cellulose derivatives, it was possible to obtain the optimal formula of the drug product similar to in-vitro conditions to the reference drug. Out of all the tested excipients, the type of cellulose microcrystalline was found to have the most critical influence on both physical and analytical properties of the pharmaceutical formulation.

Key words: wet granulation, dissolution profile, cellulose derivatives, drug formulation technology 


\section{Introduction}

Cellulose is one of the most commonly used polymers in pharmaceutical technology. It is a high-molecular-weight linear biopolymer consisting of $\mathrm{D}$-glucose units joined by $\beta$ - $(1,4)$ linkages. It is a biodegradable, low-cost, renewable, and easily accessible material with high bio-compatibility, which makes its use so common in various fields. ${ }^{1}$

In pharmaceutical technology, there are several cellulose derivatives which play a different role in the product formulation, i.e., tablet filler (cellulose microcrystalline - MCC), binder (ether derivatives: hydroxypropyl methylcellulose - HPMC, hydroxypropylcellulose, methylcellulose, ethylcellulose), superdisintegrant (croscarmellose sodium), and film-coating agent (the above-mentioned ether derivatives). They can also be used to create modified-release drug products as well as osmotic and bioadhesive delivery systems. What is more, cellulose derivatives are gaining more and more popularity in nanotechnology due to the possibility of obtaining compounds such as nanofibrillar cellulose and cellulose nanocrystal. ${ }^{1-4}$

Cellulose microcrystalline is a purified, partially depolymerized cellulose. It is a white, crystalline powder with porous particles. It is commercially available in several grades which have different properties and applications. ${ }^{5} \mathrm{Hy}$ droxypropyl methylcellulose, also known as hypromellose, is a partly $O$-methylated and $O$-(2-hydroxypropylated) cellulose. It is commercially available in different grades that vary in viscosity properties and the extent of substitution. Hypromellose is usually used as binder in the wet granulation process in concentrations up to $5 \% \mathrm{w} / \mathrm{w} .{ }^{5,6}$ Croscarmellose sodium is a cross-linked polymer of carboxymethylcellulose sodium. It belongs to the superdisintegrant group, i.e., the substances which facilitate fast disintegration and can be used in a smaller quantity than disintegrants, usually up to $5 \% \mathrm{w} / \mathrm{w}$ in the case of tablets. ${ }^{4,5}$

The above-mentioned cellulose derivatives were used during the development of a generic drug product with an active substance of Biopharmaceutics Classification System (BCS) class II. The influence of the said excipients (their type, grade, amount per tablet, and/or distribution in the tablet) on the physical and analytical attributes of the product was examined. The reference drug is considered as very rapidly dissolving, i.e., at least $85 \%$ of the labeled amount of the drug substances is dissolved within 15 min. ${ }^{7}$ The developed generic product has to fulfill the same dissolution criteria. The qualitative composition of the prepared batches is similar to the composition of the reference product. In both cases, the MCC, HPMC and croscarmellose sodium polymers were used.

The BCS is a scientific framework which helps to classify active substances regarding their solubility and permeability. The active substance which was used in the study belongs to BCS class II. This means that it shows low water solubility and high permeability. In recent years, the number of the newly developed drugs which have poor solubility properties has significantly increased. It has been stated that among new drug candidates, almost 70\% show poor water solubility. When the active substance has solubility limitations, its bioavailability can be significantly affected, even if the substance is highly permeable. Therefore, the solubility of the active substance is a very important physical property, and thus in vitro dissolution testing can play a key role in drug development. ${ }^{8-10}$

\section{Material and methods}

\section{Material}

The following materials were used: active substance of BCS class II, lactose monohydrate, MCC PH200, MCC PH101, croscarmellose sodium, HPMC 6cP, HPMC 3cP, sodium lauryl sulfate, and magnesium stearate. All substances used in the study were purchased from external suppliers.

\section{Methods}

\section{Pre-formulation studies}

During the pre-formulation studies, the Raman spectrum was performed for the active substance used in the study and the reference product in order to check that the same polymorphic form of the active substance as in the reference product was used. The parameters of powder Xray diffraction measurements were as follows: instrument - PANanlytical X'Pert PRO MPD; radiation: $\mathrm{Cu} K \alpha$, voltage: $40 \mathrm{kV}$, anode current: $40 \mathrm{~mA}$, goniometer: PW3050/60, scan rate: $0.0305 \mathrm{o} / \mathrm{s}$, step size: $0.0131^{\circ}$, sample holder: PW181/25\&40 (transmission, sample between foils), sample spinner: PW3064/60 (reflection/transmission spinner), sample spin rate: $1 \mathrm{rpm}$, detector: PIXcel (PW3018/00).

What is more, the particle size measurement of the active substance was performed using the Mastersizer 2000 particle size analyzer.

\section{Preparation of tablets via high-shear granulation process}

The active substance, lactose monohydrate, MCC, croscarmellose sodium, and hypromellose were put into a high-shear mixer. The granulating fluid was prepared by dispersing HPMC in water and, in the next step, the addition and dissolution of sodium lauryl sulfate. After mixing the dry powders, the granulation fluid was added into the high-shear mixer and the granulation step was performed. The wet granules were sieved and dried in a fluid-bed dryer. The dried granules were sieved, and the outer phase was added and mixed. The final granules were compressed into tablets using the Riva Piccola laboratory rotary tablet press machine with 8 punch sets fitted in the tablet press turret. The compression force used 
during the tableting process was in the range between 4 and $6 \mathrm{kN}$. The rotation speed was $15 \mathrm{rpm}$. The obtained tablets had a diameter of $5.5 \mathrm{~mm}$.

\section{Preparation of tablets via fluid-bed granulation process}

The active substance, lactose monohydrate, MCC, croscarmellose sodium and hypromellose were put into a fluid-bed granulator. The granulating fluid was prepared by dispersing HPMC in water and, in the next step, the addition and dissolution of sodium lauryl sulfate. After mixing the dry powders, the granulation fluid was added into the fluid-bed granulator, and the granulation and drying step were performed. The dried granules were sieved, and the outer phase was added and mixed. The final granules were compressed into tablets using the Riva Piccola laboratory rotary tablet press machine with 8 punch sets fitted in the tablet press turret. The compression force used during the tableting process was in the range between 4 and $6 \mathrm{kN}$. The rotation speed was $15 \mathrm{rpm}$. The obtained tablets had a diameter of $5.5 \mathrm{~mm}$.

\section{Determination of bulk density and tapped density}

The final granulate was taken into a 250-milliliter measuring cylinder and the initial volume was recorded. The measuring cylinder was tapped the specified number of times using the ERWEKA tapped volumeter. The bulk density and tapped density were calculated according to the following formulas:

$$
\text { bulk density }=\frac{\text { weight of the final granulate }}{\text { initial volume }}[\mathrm{g} / \mathrm{mL} \text { ? }]
$$

tapped density $=\frac{\text { weight } \text { of the final granulate }}{\text { final volume after tapping }}[\mathrm{g} / \mathrm{mL}$ ? $]$

\section{Determination of Hausner ratio}

The Hausner ratio was calculated based on the following formula:

$$
\text { Hausner ratio }=\frac{\text { tapped density }}{\text { bulk density }}
$$

\section{Determination of Carr's compressibility index}

The Carr's index was calculated based on the following formula:

$$
\text { Carr's index }=\frac{\text { tapped density }- \text { bulk density }}{\text { bulk density }} \times 100
$$

\section{Flowability}

The flow properties of the final granules were determined using a granulate tester (ERWEKA GTB; ERWE$\mathrm{KA})$. A minimum of $100 \mathrm{~g}$ of the granules were introduced into a dry funnel whose bottom opening had been blocked. In the next step, the bottom opening of the funnel was unblocked and the sample flowed out of the funnel. Flowability was determined as the time needed for the $100 \mathrm{~g}$ of the sample to flow out of the funnel and as the time needed for the $100 \mathrm{~mL}$ of the sample to flow out of the funnel. The diameter of the nozzle used in the analysis was $10 \pm 0.01 \mathrm{~mm}$.

\section{Determination of particle size distribution}

The degree of fineness of the final granulate was established using the Analysette 3 PRO vibratory sieve shaker. The assessment of the particle size distribution of the final granules was evaluated by allowing the material to pass through a series of sieves $(100 \mu \mathrm{m}, 180 \mu \mathrm{m}, 250 \mu \mathrm{m}, 355 \mu \mathrm{m}, 500 \mu \mathrm{m}$, and $800 \mu \mathrm{m})$ and weighing the amount of granules that was stopped by each sieve as a fraction of the whole mass.

\section{Tablet hardness}

The tablet hardness was determined using the MultiCheck 3 tester (ERWEKA). The measurements were conducted on 10 tablets of each batch.

\section{Friability test}

The friability test was conducted using the TDR 100 ERWEKA friability tester (ERWEKA). In order to perform the test, a sample of minimum $6.5 \mathrm{~g}$ of tablets was weighted. Before weighing, any loose dust from the tablets was removed. After weighing, the tablets were placed into the drum. The drum was rotated 100 times. After that, the tablets were removed from the drum and weighted again in order to establish the weight loss.

\section{Disintegration time}

The disintegration time of the tablets was determined using the Pharma Test PTZ AUTO. The test was conducted on 6 tablets of each batch. In order to perform the test, 1 dosage unit was placed in each of the 6 tubes of the basket and a disc was added. The test was performed using water as medium at a temperature of $37 \pm 2^{\circ} \mathrm{C}$. According to the current edition of the European Pharmacopoeia (Ph. Eur.), the tablets should disintegrate in less than 15 min. ${ }^{11}$

\section{Dissolution profile}

In order to determine the dissolution profile of the tablets, a paddle apparatus (Apparatus II USP) and a UV-VIS spectrophotometer were used. The test was 
conducted on 6 tablets of each batch and the results were compared to the results of the reference product. In order to establish similarity between the tested batches and the reference product, the following dissolution media were applied:

$-0.2 \%$ sodium dodecyl sulfate (SDS) in acetate buffer $\mathrm{pH} 4.5$;

$-0.1 \mathrm{~N}$ hydrochloric acid $(\mathrm{HCl})$;

- acetate buffer pH 4.5;

- phosphate buffer pH 6.8 .

The rest of the dissolution conditions were identical for each dissolution medium: dissolution apparatus - type II with paddle agitators; volume of dissolution medium: $500 \mathrm{~mL}$; paddle speed: $75 \mathrm{rpm}$; temperature: $37 \pm 0.5^{\circ} \mathrm{C}$; duration time: $60 \mathrm{~min}$.

The volume of the dissolution medium was decreased from a standard value of $900 \mathrm{~mL}$ to $500 \mathrm{~mL}$ due to the low absorbance of the active substance. The European Pharmacopoeia allows using dissolution medium in volumes 500-1000 mL. ${ }^{11}$

A dissolution profile analysis was conducted according to the following description: The tablets were added to each of the 6 apparatus vessels containing the dissolution medium heated to the prescribed temperature. The process was started with a rotation speed of $75 \mathrm{rpm}$. During the test, samples of the solution were taken at the following time points: $5 \mathrm{~min}, 10 \mathrm{~min}, 15 \mathrm{~min}, 20 \mathrm{~min}, 30 \mathrm{~min}$, $45 \mathrm{~min}, 50 \mathrm{~min}$, and $60 \mathrm{~min}$. The samples were filtered through a 10-micrometer filter. Next, the absorbance value of the test solutions and a suitable standard solution were determined spectrophotometrically at a wavelength of 200-400 nm, using 10-millimeter cuvettes, against the dissolution medium as a blank.

The above-mentioned analysis is specific, i.e., the blank solution and the solution of all known impurities for the active substance do not show any absorbance at a wavelength characteristic for the active substance. What is more, the spectrum obtained for the test solution and the standard solution are similar and show the maxima of absorbance at the same wavelengths $( \pm 2 \mathrm{~nm})$.

The first sample during the analysis was collected after $5 \mathrm{~min}$ of testing. Although the disintegration time of the tablets is very short ( $<5 \mathrm{~min})$, it does not mean that the active substance is already fully dissolved in the medium after the disintegration. The active substance releases from the surface of the tablet as well as from the tablet residue after the disintegration.

\section{Results and discussion}

\section{Pre-formulation study}

The active substance is a white crystalline powder, practically insoluble in water $(<10 \mathrm{mg} / \mathrm{L})$, in aqueous acidic medium $(<10 \mathrm{mg} / \mathrm{L}$ in $0.1 \mathrm{M} \mathrm{HCl})$ or in higher $\mathrm{pH}$
$(<10 \mathrm{mg} / \mathrm{L}$ for $\mathrm{pH} 9.0)$. It is slightly soluble in organic solvents and its $\log \mathrm{P}$ value is at the level of 1.5 . The active substance has more than one polymorphic form. However, the polymorphic form used in the study was confirmed via the X-ray diffraction analysis to be the same as the one in the reference product.

The active substance in the reference product is in a micronized form. Therefore, the active substance used in the study underwent a micronization process as well. In order to check its particle size distribution, the active substance sample was measured via the laser diffraction method and the results show that $d(0.9)$, which corresponds to $90 \%$ of the cumulative undersize distribution, is $<30 \mu \mathrm{m}$.

\section{Formulation study}

In order to obtain the most suitable formula which would be similar to the reference product, batches F1-F9 were produced. Batches F1-F4 differed in the amount of HPMC 6cP. Hydroxypropyl methylcellulose plays a binder role in the tablet formulation. In the case of batch F5, HPMC 6cP was replaced with HPMC of lower viscosity, i.e., 3cP. One batch - F6 - was produced using different manufacturing technology from the rest of the trials - the granulate was obtained via the fluid-bed granulation. Usually, it is possible to obtain finer granules using the wet granulation process via a fluid-bed granulator instead of a highshear mixer. The aim of preparing batch F6 was to check if the manufacturing of significantly smaller granules would have an influence on the dissolution profile results. The qualitative as well as quantitative composition of batch F6 is exactly the same as for batch F5. What is more, the granulation fluid was identical and all the other steps of the process, except the granulation part, were kept the same. In the case of batches F7-F9, MCC PH200 which was used as a tablet filler was replaced with MCC of finer particles, i.e., PH101. More detailed information about the batch compositions are presented in Table 1.

\section{Evaluation of granules}

In order to characterize the powder flow of the prepared batches F1-F9, the following methods were used: flow rate through an orifice, angle of repose, the compressibility index, and the Hausner ratio (Table 2).

The flow rate of the granules was measured in 2 ways: as the time it takes for $100 \mathrm{~g}$ of the granules to pass through the orifice and as the time it takes for $100 \mathrm{~mL}$ of the granules to pass through the orifice. The best results (the shortest time) in the case of both methods were obtained for batch F4, which contains MCC of coarser particles (PH200) and HPMC of higher viscosity (6cP). The worst results (the longest time) were found for batch $\mathrm{F} 7$, where $\mathrm{MCC}$ of coarser particles was replaced with MCC of finer particles (PH101) and HPMC 6cP was replaced with HPMC 3cP. 
Table 1. Composition of prepared batches F1-F9

\begin{tabular}{|c|c|c|c|c|c|c|c|c|c|}
\hline \multicolumn{10}{|c|}{ Qualitative and quantitative composition of the prepared batches [\%/tablet] } \\
\hline Formulation code & $\mathrm{F} 1$ & $\mathrm{~F} 2$ & F3 & $\mathrm{F} 4$ & F5 & F6 & F7 & F8 & F9 \\
\hline Manufacturing technology & \multicolumn{5}{|c|}{$\begin{array}{l}\text { wet granulation } \\
\text { via high-shear mixer }\end{array}$} & $\begin{array}{l}\text { wet granulation } \\
\text { via fluid-bed granulator }\end{array}$ & \multicolumn{3}{|c|}{$\begin{array}{l}\text { wet granulation } \\
\text { via high-shear mixer }\end{array}$} \\
\hline \multicolumn{10}{|c|}{ Inner phase } \\
\hline Active substance & $\leq 12.5$ & $\leq 12.5$ & $\leq 12.5$ & $\leq 12.5$ & $\leq 12.5$ & $\leq 12.5$ & $\leq 12.5$ & $\leq 12.5$ & $\leq 12.5$ \\
\hline Lactose monohydrate & 35.38 & 35.00 & 35.5 & 34.79 & 34.79 & 34.79 & 34.79 & 34.79 & 34.79 \\
\hline MCC PH200 & 52.25 & 51.88 & 52.38 & 51.34 & 51.34 & 51.34 & - & - & - \\
\hline MCC PH101 & - & - & - & - & - & - & 51.34 & 51.34 & 51.34 \\
\hline Croscarmellose sodium & 2.50 & 2.50 & 5.00 & 5.00 & 5.00 & 5.00 & 5.00 & 5.00 & 2.50 \\
\hline HPMC 6cP & 0.63 & 1.00 & 1.00 & 1.88 & - & - & - & 1.88 & 1.88 \\
\hline HPMC 3CP & - & - & - & - & 1.88 & 1.88 & 1.88 & - & - \\
\hline \multicolumn{10}{|c|}{ Granulating fluid } \\
\hline HPMC 6cP & 0.63 & 1.00 & 1.00 & 1.88 & - & - & - & 1.88 & 1.88 \\
\hline HPMC 3cP & - & - & - & - & 1.88 & 1.88 & 1.88 & - & - \\
\hline Sodium lauryl sulfate & 2.00 & 2.00 & 1.00 & 1.00 & 1.00 & 1.00 & 1.00 & 1.00 & 1.00 \\
\hline Water & 27.00 & 27.00 & 27.00 & 27.00 & 27.00 & 27.00 & 27.00 & 27.00 & 27.00 \\
\hline \multicolumn{10}{|c|}{ Outer phase } \\
\hline Croscarmellose sodium & 2.50 & 2.50 & - & - & - & - & - & - & 2.50 \\
\hline Magnesium stearate & 1.00 & 1.00 & 1.00 & 1.00 & 1.00 & 1.00 & 1.00 & 1.00 & 1.00 \\
\hline
\end{tabular}

MMC - cellulose microcrystalline; HPMC - hydroxypropyl methylcellulose

The angle of repose reflects the resistance to movement between the particles. According to European Pharmacopoeia (Ph. Eur.), when the angle of repose is above 50 degrees, the flow is rarely acceptable for manufacturing purposes. ${ }^{11}$ In the case of all batches, the angle of repose was below 50 degrees. However, there is a significant difference in the results between the batches with MCC of coarser particles and the batches in which MCC PH200 was replaced with MCC PH101.

The next 2 methods used in order to evaluate the flow characteristics of the granules are compressibility index and the Hausner ratio. Both of the methods are determined by measuring the bulk and tapped volume of the final granules. According to the flowability scale $(\mathrm{Ph}$. Eur.), results above $25 \%$ for the compressibility index and 1.34 for the Hausner ratio indicate poor flow properties. ${ }^{11}$
The flow character for most of the prepared batches was determined as good (compressibility index: 11-15\%, Hausner ratio: 1.12-1.18). The worst results were obtained for batch F8 (the flow character determined as passable) and the best results were obtained for batch F2 (the flow character determined as excellent).

The particle size distribution for all prepared batches was determined via the sieve analysis (Table 3). There is a significant difference between the granule particle size of the batches prepared using MCC PH200 and the batches where MCC PH200 was replaced with MCC PH101. Due to the fact that MCC is present in the composition of batches in high amounts, it is obvious that it has a significant influence on the particle size distribution of the final granules. In the case of batches F7-F9, approx. 50\% of the particles are $<100 \mu \mathrm{m}$, which means that the granules are

Table 2. Flow properties of granules

\begin{tabular}{|l|c|c|c|c|c|c|c|}
$\begin{array}{c}\text { Batch } \\
\text { number }\end{array}$ & $\begin{array}{c}\text { Bulk density } \\
{[\mathrm{g} / \mathrm{mL}]}\end{array}$ & $\begin{array}{c}\text { Tapped density } \\
{[\mathrm{g} / \mathrm{mL}]}\end{array}$ & Hausner ratio & $\begin{array}{c}\text { Carr's compressibility index } \\
{[\%]}\end{array}$ & $\begin{array}{c}\text { Flow rate } \\
{[\mathrm{s} / 100 \mathrm{~g}]}\end{array}$ & $\begin{array}{c}\text { Volume flow rate } \\
{[\mathrm{s} / 100 \mathrm{~mL}]}\end{array}$ & $\begin{array}{c}\text { Angle of repose } \\
\text { F1 }\end{array}$ \\
\hline F2 & 0.53 & 0.60 & 1.14 & 12.0 & $36.5 \pm 0.97$ & $18.2 \pm 0.10$ & $39.5 \pm 1.17$ \\
F3 & 0.54 & 0.60 & 1.11 & 9.6 & $27.3 \pm 0.17$ & $12.3 \pm 0.06$ & $40.8 \pm 0.49$ \\
F4 & 0.50 & 0.56 & 1.13 & 11.2 & $27.8 \pm 0.32$ & $11.9 \pm 0.12$ & $39.3 \pm 0.38$ \\
F5 & 0.48 & 0.54 & 1.13 & 11.2 & $21.9 \pm 0.52$ & $9.2 \pm 0.06$ & $38.8 \pm 0.75$ \\
F6 & 0.49 & 0.55 & 1.13 & 11.2 & $24.7 \pm 6.27$ & $18.4 \pm 3.82$ & $38.2 \pm 1.65$ \\
F7 & 0.46 & 0.53 & 1.16 & 13.6 & $32.4 \pm 0.10$ & $12.3 \pm 0.15$ & $38.4 \pm 0.40$ \\
F8 & 0.52 & 0.63 & 1.21 & 17.6 & $49.1 \pm 12.54$ & $14.7 \pm 0.46$ & $45.6 \pm 0.95$ \\
F9 & 0.51 & 0.64 & 1.26 & 20.89 & $28.5 \pm 0.64$ & $13.2 \pm 1.43$ & $46.1 \pm 1.70$ \\
\hline
\end{tabular}


Table 3. Particle size distribution of granules

\begin{tabular}{|c|c|c|c|c|c|c|c|}
\hline \multirow{2}{*}{$\begin{array}{l}\text { Batch } \\
\text { number }\end{array}$} & \multicolumn{7}{|c|}{ Sieve analysis of final granulate [\%] } \\
\hline & $<100 \mu \mathrm{m}$ & $100-180 \mu \mathrm{m}$ & $180-250 \mu \mathrm{m}$ & $250-355 \mu \mathrm{m}$ & $355-500 \mu \mathrm{m}$ & $500-800 \mu \mathrm{m}$ & $>800 \mu \mathrm{m}$ \\
\hline F1 & 29.1 & 22.6 & 20.6 & 21.6 & 5.2 & 0.7 & 0.2 \\
\hline F2 & 21.6 & 22.4 & 21.1 & 23.5 & 9.6 & 1.6 & 0.2 \\
\hline F3 & 22.3 & 20.9 & 20.9 & 23.8 & 9.1 & 2.9 & 0.1 \\
\hline F4 & 16.4 & 16.4 & 18.3 & 26.8 & 17.0 & 4.8 & 0.2 \\
\hline F5 & 21.1 & 19.8 & 19.8 & 24.9 & 12.3 & 1.9 & 0.1 \\
\hline F6 & 31.7 & 32.1 & 21.3 & 13.7 & 1.0 & 0.2 & 0 \\
\hline F7 & 54.3 & 17.4 & 7.4 & 7.8 & 10.9 & 2.0 & 0.1 \\
\hline F8 & 51.8 & 14.8 & 5.9 & 8.2 & 14.3 & 4.9 & 0.1 \\
\hline F9 & 47.8 & 16.1 & 6.9 & 9.1 & 15.2 & 4.8 & 0.1 \\
\hline
\end{tabular}

very fine. Batch F6, which was prepared via the fluid-bed granulation, is characterized by an intermediate particle size distribution, placing itself between batches F7-F9 and F2-F5. Very fine particles were also obtained in batch F1, in which HPMC 6cP was added at the lowest amount. Batches F2-F5 had the largest particle size and, according to $\mathrm{Ph}$. Eur., are determined as moderate fine, i.e., the median size (X50) of the particles is in the range of $180-355 \mu \mathrm{m} .{ }^{11}$

\section{Evaluation of tablet cores}

The following physical parameters of the tablet cores were determined: tablet hardness, disintegration time and tablet friability (Table 4). For all of the batches, the mean tablet hardness is in the range of 50-70 N. For all of the batches, the disintegration time is $<15 \mathrm{~min}$, which complies with the requirements for uncoated tablets. ${ }^{11}$ The shortest disintegration time was observed in the case of batch F8 and the longest disintegration time was observed for batch F4. All batches present very satisfying friability test results. In all cases, the tablet friability is below or close to $0.1 \% \mathrm{w} / \mathrm{w}$.

All batches underwent the dissolution profile analysis. The results obtained were compared to the results of the dissolution profile for the reference sample.

Table 4. Physical parameters of tablet cores (compression force during tableting $-6 \mathrm{kN}$ )

\begin{tabular}{|l|c|c|c|c|}
\multirow{2}{*}{$\begin{array}{c}\text { Batch } \\
\text { number }\end{array}$} & \multirow{2}{*}{ Hardness [N] } & \multicolumn{2}{|c|}{ Disintegration time [min] } & \multirow{2}{*}{ Friability [\%] } \\
\cline { 1 - 3 } F1 & $59 \pm 1.84$ & $2: 52-3: 00$ & $2: 56 \pm 0: 03$ & 0.069 \\
F2 & $58 \pm 1.35$ & $3: 24-3: 50$ & $3: 37 \pm 0: 10$ & 0.037 \\
F3 & $67 \pm 2.11$ & $3: 10-3: 50$ & $3: 33 \pm 0: 16$ & 0.120 \\
F4 & $71 \pm 2.46$ & $3: 50-4: 30$ & $4: 10 \pm 0: 16$ & 0.054 \\
F5 & $65 \pm 3.11$ & $3: 12-3: 30$ & $3: 21 \pm 0: 07$ & 0.013 \\
F6 & $60 \pm 4.11$ & $3: 38-3: 56$ & $3: 50 \pm 0: 07$ & 0.006 \\
F7 & $58 \pm 3.27$ & $2: 32-3: 02$ & $2: 48 \pm 0: 10$ & 0.096 \\
F8 & $68 \pm 2.99$ & $1: 54-2: 18$ & $2: 06 \pm 0: 10$ & 0.019 \\
F9 & $62 \pm 2.99$ & $2: 22-2: 52$ & $2: 37 \pm 0: 10$ & 0.032 \\
\hline
\end{tabular}

The results of the dissolution profile in chosen media for batches F1-F9 (Fig. 1) show that by increasing the amount of HPMC it was possible to obtain a faster drug release. What is more, the replacement of HPMC $6 \mathrm{cP}$ with HPMC of lower viscosity $(3 \mathrm{cP})$ resulted in slightly better results, more similar to the reference product. The effect of dissolution profile improvement was especially visible when the granulation method was changed from high-shear mixing to fluid-bed granulation. However, the best dissolution profile results were obtained when MCC of coarser particles was replaced with MCC of finer particles, regardless of the type of HPMC used and the distribution of croscarmellose sodium.

For rapidly dissolving products, 2 dissolution profiles can be considered as similar without further mathematical evaluation when $>85 \%$ of the active substance dissolves within $15 \mathrm{~min}$. The comparison of dissolution profile results in acetate buffer $\mathrm{pH} 4.5$ with $0.2 \%$ SDS after 15 min of testing is provided in Table 5 . Based on the results obtained, it can be stated that batches F6-F9 are similar to the reference product.

The level of similarity between the developed product and the reference drug should be as high as possible. One of the methods which can evaluate the level of similarity in in-vitro conditions is performing the dissolution profile analysis in 3 different media. Therefore, 3 different batches were chosen: F5, F6 and F9, and the analysis of the dissolution profile in the following dissolution media was performed: $0.1 \mathrm{~N} \mathrm{HCl}$, acetate buffer $\mathrm{pH} 4.5$ and

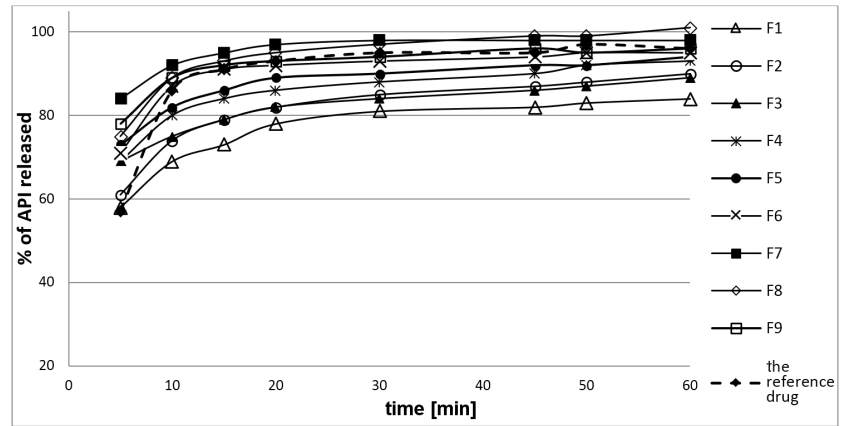

Fig. 1. Dissolution profile results for batches F1-F9 in acetate buffer $\mathrm{pH} 4.5$ with $0.2 \%$ sodium dodecyl sulfate 
phosphate buffer pH 6.8 (Fig. 2). The analysis carried out under acidic conditions $(0.1 \mathrm{~N} \mathrm{HCl})$ show significant differences between the tested batches. The worst results were obtained in the case of batch F5. Slightly better results were obtained for batch F6, which has the same qualitative and quantitative composition as batch F5, but it was produced with a different wet granulation technique, i.e., via the fluid-bed granulation. The results for batches F5-F6 are significantly lower than for batch F9 and the reference product. Out of all the batches tested, batch F9 seems to be the most similar to the reference drug.

\section{Conclusions}

It was found that cellulose derivatives presented in the composition of a drug product with an active substance of BCS class II had a significant influence on the physi- cal and analytical attributes of the product. Out of all the prepared batches, the best results with regard to granule properties were obtained for batches MCC of coarser particles and HPMC of higher viscosity. However, the results of the dissolution profile for these batches differed significantly when compared to the results of the reference product. The dissolution profile enhanced when HPMC of higher viscosity was replaced with HPMC of lower viscosity (batch F5). What is more, the dissolution profile was even better when the granulation technology used in batch F5 was changed from high-shear mixing to fluid-bed granulation (batch F6) while using the same qualitative and quantitative composition. However, despite very promising dissolution profile results in $0.2 \%$ SDS in acetate buffer, which was established as the chosen dissolution medium, the analysis in 3 different media showed significant differences in acidic conditions, i.e., $0.1 \mathrm{~N} \mathrm{HCl}$, between batch $\mathrm{F} 6$ and the reference product.

Table 5. Comparison of dissolution profile results in acetate buffer $\mathrm{pH} 4.5$ with $0.2 \%$ sodium dodecyl sulfate (SDS) after 15 min of testing

\begin{tabular}{|c|c|c|c|c|c|c|c|c|c|c|c|}
\hline \multicolumn{2}{|c|}{ Batch } & Reference product & $\mathrm{F} 1$ & $\mathrm{~F} 2$ & F3 & $\mathrm{F} 4$ & F5 & F6 & F7 & F8 & F9 \\
\hline \multirow{4}{*}{$\begin{array}{l}\% \text { of API dissolved } \\
\text { in } 15 \mathrm{~min}\end{array}$} & average for 6 samples & 90 & 73 & 79 & 79 & 70 & 86 & 91 & 95 & 93 & 92 \\
\hline & $\min$ & 85 & 71 & 76 & 77 & 66 & 82 & 86 & 92 & 93 & 90 \\
\hline & $\max$ & 93 & 78 & 82 & 82 & 74 & 90 & 96 & 97 & 94 & 93 \\
\hline & RSD [\%] & 3.6 & 5.5 & 3.9 & 2.5 & 4.4 & 3.6 & 4.7 & 2.5 & 0.6 & 1.1 \\
\hline \multicolumn{2}{|c|}{ Is the batch similar to the reference product? } & - & no & no & no & no & yes/no* & yes & yes & yes & yes \\
\hline
\end{tabular}

API - active pharmaceutical ingredients; RSD - relative standard deviation; ${ }^{*}$ The average is above $85 \%$; however, some of the results are still below $85 \%$.
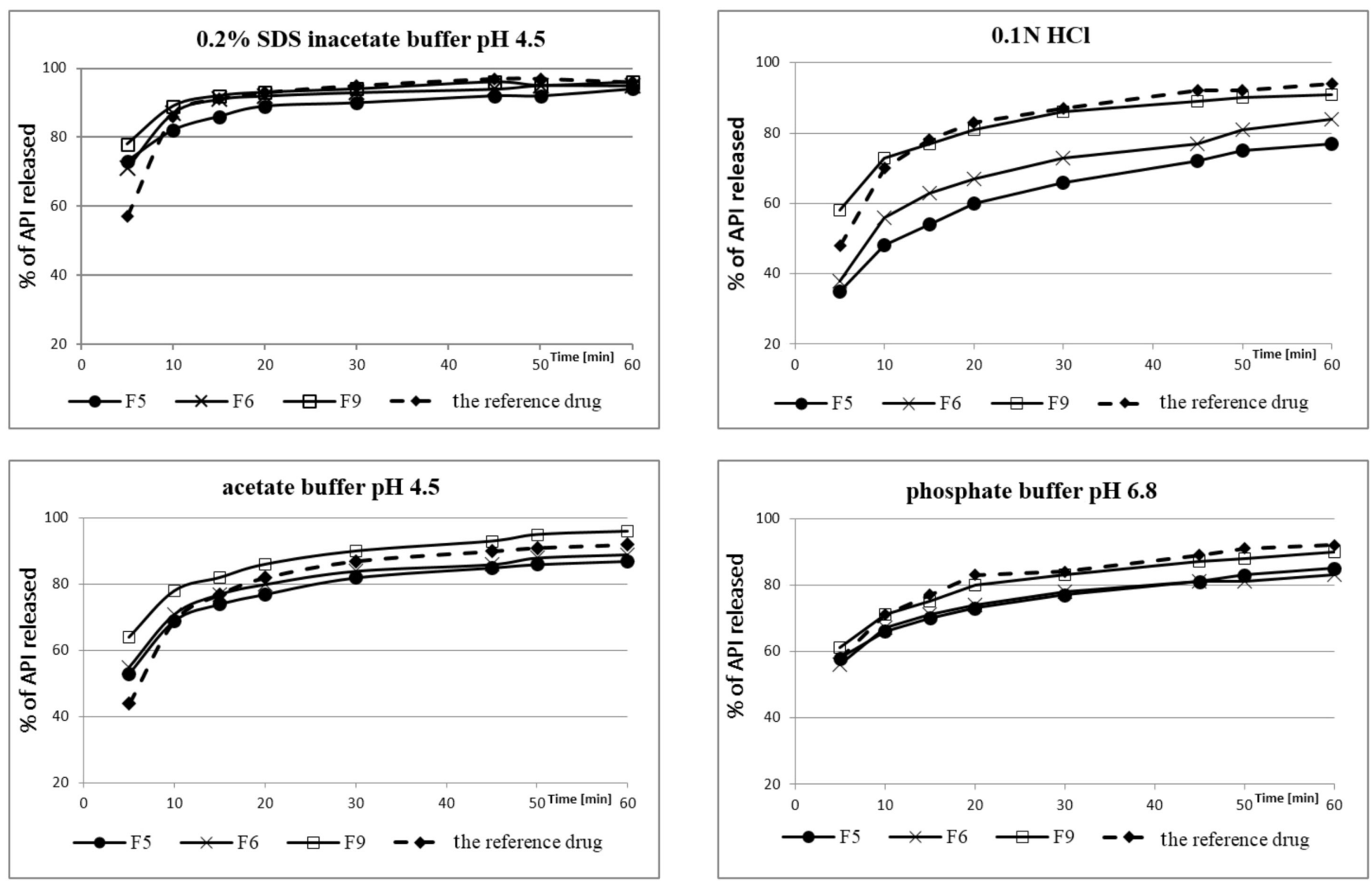

Fig. 2. Dissolution profile results in different media for chosen batches F5, F6 and F9 in comparison to the reference product 
Therefore, further changes in the composition are required. The preparation of batches F7-F9 showed that the type of MCC used had the most critical influence on the dissolution profile out of all the cellulose derivatives tested. The dissolution profile in chosen media was similar in the case of all batches where MCC of coarser particles was replaced with $\mathrm{MCC}$ of finer particles, regardless of the HPMC viscosity type used and the distribution of croscarmellose sodium. The results of the dissolution profile in 3 different media for the chosen batch F9 showed very high similarity to the reference product.

\section{ORCID iDs}

Magdalena Domosławska (1) https://orcid.org/0000-0002-4896-4648

Renata Pawlak-Morka (10 https://orcid.org/0000-0001-8828-6661

Łukasz Dobrzyński (10) https://orcid.org/0000-0002-6289-7242

Monika Herda (i) https://orcid.org/0000-0002-3825-1687

\section{References}

1. Halib N, Perrone F, Cemazar M, et al. Potential applications of nanocellulose-containing materials in the biomedical field. Materials. 2017;10:977.

2. Shokri J, Adibkia K. Application of Cellulose and Cellulose Derivatives in Pharmaceutical Industries. In: Van De Ven TGM, ed. Cellulose Medical, Pharmaceutical and Electronic Applications. Intech; 2013.

3. Kubiak-Tomaszewska G, Tomaszewski P, Pachecka J. Hypromellose in pharmaceutical technology of capsules and other medicinal product dosage forms. Pediatr Med Rodz. 2011;7(3):271-276.

4. Rawat S, Derle DV, Fukte SR, Shinde PR, Parve BS. Superdisintegrants: An overview, World J Pharm Pharm Sci. 2014;3(5):263-278.

5. Rowe RC, Sheskey PJ, Quinn ME. Handbook of Pharmaceutical Excipients. $6^{\text {th }}$ ed. London; 2009:129-133, 206-208.

6. Hamed E, Moe D, Khankari R, Hontz J. Binders and Solvents. In: Parikh DM, Raton B, ed. Handbook of Pharmaceutical Granulation Technology. $2^{\text {nd }}$ ed. North Carolina, Pinehurs: PharmaceuTech Inc.; 2005:109-125.

7. US Department of Health and Human Services Food and Drug Administration Center for Drug Evaluation and Research. Waiver of in Vivo Bioavailability and Bioequivalence Studies for ImmediateRelease Solid Oral Dosage Forms Based on a Biopharmaceutics Classification System Guidance for industry. US Department of Health and Human Services Food and Drug Administration Center for Drug Evaluation and Research; 2017.

8. Khadka P, Kim JRH, Kim I, et al. Pharmaceutical particle technologies: An approach to improve drug solubility, dissolution and bioavailability. AJPS. 2014;9(6)304-316.

9. US Department of Health and Human Services Food and Drug Administration Centre for Drug Evaluation and Research. Guidance for Industry Dissolution Testing of Immediate Release Solid Oral Dosage Forms. US Department of Health and Human Services Food and Drug Administration Centre for Drug Evaluation and Research; 1997.

10. International Council for Harmonisation of Technical Requirements for Pharmaceuticals for Human Use. ICH Harmonised Guideline. Biopharmaceutics Classification System-Based Biowaivers M9 [draft version]. Geneva: International Council for Harmonisation of Technical Requirements for Pharmaceuticals for Human Use; 2018.

11. European Pharmacopeia. $7^{\text {th }}$ Edition. Vol. 1. https://pl.scribd.com/ document/367962556/European-Pharmacopoeia-7-0-Vol-1-pdf 